\title{
Papel de trabalho, carreira, satisfação de vida e ajuste na aposentadoria ${ }^{1}$
}

\author{
Samantha de Toledo Martins Boehs ${ }^{2}$ \\ Universidade Federal do Paraná, Curitiba-PR, Brasil \\ Narbal Silva \\ Universidade Federal de Santa Catarina, Florianópolis-SC, Brasil
}

\section{Resumo}

O advento da aposentadoria pode gerar um desequilíbrio na organização dos papéis que as pessoas desempenham durante suas vidas. O presente estudo, de abordagem qualitativa, teve como objetivo compreender as possíveis relações entre o papel do trabalho durante a carreira e a satisfação de vida/ajuste na aposentadoria em 13 aposentados de uma empresa multinacional. A partir da utilização da técnica da trajetória sócio profissional e da entrevista semiestruturada, os resultados apontaram para o alto envolvimento com o trabalho durante a carreira e para quatro fatores principais que influenciam a satisfação de vida na aposentadoria, sendo eles: o fator financeiro, a rede social de apoio, a voluntariedade/involuntariedade da decisão de aposentar e a realização de trabalho voluntário.

Palavras-chave: trabalho, orientação vocacional, bem-estar, aposentadoria

\section{Abstract: Role of work, career, life satisfaction and adjustment in retirement}

The advent of retirement can generate an imbalance in the organization of the roles that people play in their lives. The purpose of this qualitative study was to understand the possible relationships between the role of work during the career and life satisfaction/adjustment to retirement in 13 retirees of a multinational company. Based on the use of the socio-professional trajectory technique and the semi-structured interview, the results pointed to the high involvement with work during the career and to four main factors that influence retirement life satisfaction, being: the financial factor, the social support network, voluntary/involuntary decision to retire and involvement in voluntary work.

Keywords: work, vocational guidance, welfare, retirement

\section{Resumen: Papel del trabajo, carrera, satisfacción con la vida y adaptación a la jubilación}

La llegada de la jubilación puede generar un desequilibrio en la organización de los roles que las personas desempeñan durante su vida. El presente estudio, con un enfoque cualitativo, tuvo como objetivo comprender las posibles relaciones entre el papel del trabajo durante la carrera y la satisfacción con la vida/adaptación a la jubilación en 13 jubilados de una empresa multinacional. A partir de la utilización de la técnica de trayectoria socioprofesional y de la entrevista semiestructurada, se obtuvieron resultados que señalaron el alto grado de compromiso con el trabajo durante la carrera y cuatro factores principales que influyen en el grado de satisfacción con la vida en la etapa de jubilación, a saber: el factor financiero, la red social de apoyo, la voluntariedad/involuntariedad de la decisión de jubilarse y la realización de trabajo voluntario.

Palabras clave: trabajo, orientación vocacional, bienestar, jubilación

\footnotetext{
${ }^{1}$ Este artigo é parte da Tese de doutorado desenvolvida por Samantha de Toledo Martins Boehs no Programa de Pós-Graduação em Psicologia da Universidade Federal de Santa Catarina.

${ }^{2}$ Endereço para correspondência: Universidade Federal do Paraná, Departamento de Administração Geral e Aplicada, Rua Prefeito Lothário Meissner, 632, Jardim Botânico, 80210-170, Curitiba, PR. E-mail: profsamantha.toledo@gmail.com
} 
Apesar de nos dois últimos séculos, o trabalho vir sendo considerado como algo central na vida das pessoas, nem sempre foi assim. Somente com o advento do modo de produção capitalista, o trabalho tornou-se um tema de relevância, passando a ser dimensionado como central na vida das pessoas (Borges \& Yamamoto 2014). A partir dessa concepção da importância do trabalho na vida, estudos começaram a ser desenvolvidos sobre a centralidade e o significado do trabalho (Schweitzer, Gonçalves, Tolfo, \& Silva, 2016; Tolfo \& Piccinni, 2007). Tal centralidade pode ser compreendida a partir do grau de importância que o mesmo tem na vida de um ser humano, em determinado momento da sua existência. A centralidade do trabalho supõe a presença de dois componentes: um valorativo - a centralidade absoluta - que mede o valor atribuído pelos sujeitos considerando a importância do trabalho na sua existência; e outro, sobre a centralidade relativa do trabalho, comparada a outras esferas importantes na vida (Tolfo \& Piccinni, 2007).

Para considerar a centralidade relativa do trabalho em relação aos outros papéis e buscando responder às mudanças ocorridas na sociedade, Super (1980) propôs a Teoria desenvolvimentista "Life-Span, Life-Space", na qual há a inclusão de uma gama de papéis sociais no desenvolvimento de carreira, ao invés de concentrar-se apenas no papel de trabalhador (Oliveira, Melo-Silva, \& Coleta, 2012). No presente artigo, para a compreensão dos papéis que as pessoas desempenham ao longo da vida, foi utilizada a perspectiva desenvolvimentista de carreira baseada nos conceitos de Super $(1980,1986)$ e Savickas (2002), que mencionam os diversos papéis que o ser humano desenvolve ao longo do ciclo de vida, relacionando-os ao conceito de carreira. A preocupação em compreender a carreira a partir do estudo de outros papéis, além do de trabalhador, é um ponto central para a Psicologia contemporânea, uma vez que a sociedade moderna possibilita a participação das pessoas em múltiplos papéis sociais, cabendo ao ser humano gerenciar sua participação nos mesmos, de modo a encontrar o equilíbrio entre a vida pessoal e profissional (Oliveira et al., 2012).

Nesta concepção, o conceito de carreira é definido por Super (1980) como a sequência e integração entre os papéis exercidos pela pessoa no decorrer de sua vida. O referido autor propôs um modelo de duas dimensões, denominado "Arco-íris de Carreira", em que a dimensão longitudinal (ciclo de vida) é representada na extensão do arco, e a dimensão transversal (papéis sociais) é representada pelas subdivisões que contemplam cada um dos papéis que as pessoas possuem nas organizações e em outros espaços de suas vidas.
Segundo a perspectiva desenvolvimentista de carreira, de acordo com os estágios do ciclo de vida, a pessoa pode conferir pesos diferentes ao desempenho desses papéis. Em geral, em cada etapa, dois ou três tomam um lugar central e outros são periféricos ou ausentes. Dessa forma, de acordo com a fase da vida, alguns papéis irão receber mais investimento emocional e dedicação do que outros. Super (1980) conceituou como saliência de papel a importância que cada ser humano atribui a um papel específico se correlacionado aos outros papéis que desempenha no seu contexto social (Lassance \& Sarriera, 2012; Super $\&$ Nevill, 1986) e denominou como ponto de decisão cada escolha que uma pessoa faz de assumir um novo papel, de abandonar ou de dedicar menos tempo a um papel antigo (Super, 1980).

Os papéis desempenhados no decorrer do ciclo de vida, segundo Super e Nevill (1986) são cinco: Estudo, Trabalho, Serviço Comunitário, Casa e Família, Tempo Livre. O papel relativo ao Estudo está relacionado a fazer cursos, frequentar a escola ou estudar de forma independente. O relativo ao Trabalho está ligado a realizar atividade -para alguém ou para si mesmo - em troca de remuneração ou algum outro benefício. O Serviço Comunitário compreende atividades em organizações comunitárias, políticas ou religiosas. Já o papel que se refere à Casa e à Família está relacionado às atividades de arrumar a casa, preparar refeições, fazer compras ou cuidar de algum parente. Por fim, o papel relativo ao Tempo Livre refere-se à participação em atividades esportivas, assistir TV, praticar hobbies, ir ao cinema, teatro ou shows, ler, relaxar ou não fazer nada, passar tempo com a família e amigos (Super \& Nevill, 1986).

Em decorrência da centralidade do trabalho durante a carreira regular, com o advento da aposentadoria poderá vir a acontecer um desequilíbrio na organização dos papéis, bem como uma confusão nos seus desempenhos, o que implica a necessidade de refletir sobre a redistribuição do tempo e da dedicação conferido a cada um deles. A aposentadoria pode ser concebida como um processo de transição do curso de vida, que marca o início de um novo estágio, no qual os trabalhadores precisam se adaptar às mudanças significativas que acompanham a transição com a finalidade de buscar o conforto psicológico com a vida de aposentados (Leandro-França, van Solinge, Henkens, \& Murta, 2016).

A compreensão do ajustamento à aposentadoria é um fenômeno complexo e multifatorial que tem gerado resultados distintos em pesquisas sobre o tema. Aspectos individuais, psicossociais e organizacionais têm sido apontados como influentes no ajuste e na satisfação de vida na aposentadoria (Leandro-França, 2014). No presente 
estudo será utilizado o conceito de satisfação de vida como indicativo do ajuste na aposentadoria. A satisfação de vida se caracteriza como o componente cognitivo do conceito de Bem-estar subjetivo e se refere tanto a um julgamento cognitivo de algum domínio específico, quanto a um processo de juízo e avaliação geral da própria vida (Emmons, 1986).

A boa condição financeira tem se apresentado como um dos principais preditores de ajuste na aposentadoria tendo em vista que pesquisas anteriores demonstraram, por exemplo, que possuir dificuldades financeiras no processo de transição (Amorim, França, \& Valentini, 2017; Bonsang \& Klein, 2012) e possuir filhos dependentes financeiramente (Wang, Henkens, \& Van Solinge, 2011) têm influenciado negativamente nesse processo de ajuste. As relações familiares por sua vez, também têm sido apontadas como relevantes na adaptação à aposentadoria (Heybroek, 2011; Heybroek, Haynes, \& Baxter 2015; Wang, et al., 2011). Uma vez positivas, favorecem o ajuste, mas quando demandam a dedicação integral com ascendentes e descendentes que exigem cuidado intensivo como netos e pais, podem afetar negativamente o processo de ajuste. Os estudos mostram que quanto melhores as relações com o cônjuge e com familiares melhor a adaptação (Davey \& Szinovacz, 2004; Heybroek, 2011).

Outros fatores relacionados positivamente ao ajuste e satisfação de vida na aposentadoria são: ter realizado planejamento para a aposentadoria (França et al., 2014; Leandro-França, et al., 2016, Yeung \& Zhou, 2017), aposentar-se para fazer outras atividades, engajar-se em lazer e trabalho formal (Wang, et al., 2011) ou voluntário (Krawulski, Boehs, Cruz, \& Medina, 2017; Wang, et al., 2011). Por outro lado, aposentar-se mais cedo do que o esperado (Wang et al., 2011), ou de forma involuntária e abrupta (Bonsang \& Klein, 2012; Dingemans \& Henkens, 2014) afetam negativamente a adaptação, enquanto a voluntariedade do processo de transição (Bonsang \& Klein, 2012; Heybroek et al., 2015) e estar desempregado (Heybroek, 2011; Wang, et al., 2011), antes de tornar-se aposentado, estão positivamente relacionados ao processo de ajuste e satisfação de vida.

Conforme referido anteriormente, diversos estudos nacionais e internacionais têm sido desenvolvidos sobre o papel de trabalho durante a carreira e sobre a satisfação de vida/ ajuste na aposentadoria. Entretanto, alguns artigos (Boehs, Medina, Bardagi, Luna, \& Silva, 2017; Shultz \& Wang, 2011; Wang et al., 2011) apontam para incipiência de estudos em que a aposentadoria seja compreendida a partir de uma perspectiva temporal, que considere a relação entre o papel do trabalho durante a carreira, os tipos de decisão para a aposentadoria e a satisfação de vida na aposentadoria. Para Shultz e Wang (2011), é fundamental a compreensão da aposentadoria a partir de uma visão processual, na qual as fases de preparação, tomada de decisão e ajuste sejam percebidas como um contínuo e de forma interligada. Ainda em relação a esta questão, Boehs et al. (2017), mencionam a raridade de estudos na América Latina que investiguem a aposentadoria considerando todas as etapas deste processo de maneira integrada. Os autores anteriormente referidos, em revisão da Literatura Latino-americana sobre Aposentadoria e Trabalho sob as perspectivas psicológicas, apontaram também para a raridade das publicações no Brasil e na América Latina sobre a relação entre aposentadoria e trabalho na perspectiva de pessoas que estivessem efetivamente aposentadas. Dessa forma, entendendo a aposentadoria, a partir de uma visão processual, no presente artigo são abordados os resultados de investigação empírica cujo objetivo foi compreender as possíveis relações entre o papel do trabalho durante a carreira e a satisfação de vida / ajuste na aposentadoria.

\section{Método}

Para atingir o objetivo proposto foi realizado um estudo, de abordagem qualitativa, com nível de mensuração nominal junto a profissionais que tiveram como último empregador, antes de se aposentarem pelo Instituto Nacional de Seguridade Social (INSS), uma empresa multinacional cuja sede no Brasil se encontra na cidade de Curitiba/PR, denominada na presente pesquisa, ficticiamente, de "Gama". O projeto de pesquisa deste estudo foi previamente submetido ao Comitê de Ética em Pesquisa com Seres Humanos da Universidade Federal de Santa Catarina e aprovado conforme Parecer $n^{\circ} 1322.802$, de 13 de novembro de 2015.

\section{Participantes}

Treze aposentados participaram do estudo, sendo quatro mulheres e nove homens, com idades entre $55 \mathrm{e}$ 66 anos. Nove eram casados, um solteiro e três separados. Três possuíam renda entre quatro a sete salários mínimos, quatro recebiam entre sete e dez, e seis possuíam renda mensal, maior do que dez salários mínimos. Os participantes trabalharam na empresa Gama, por período entre 15 anos, até 37 anos, e antes de se aposentarem pelo INSS ocupavam os seguintes cargos: dois de técnico, três de analista, sete de Gerência / Coordenação e um de Direção/ presidência. Visando garantir a condição de anonimato aos participantes, para diferenciá-los, optou-se por utilizar a letra "P" de participante, seguida pelo sexo e por uma 
sequência numérica definida de acordo com a ordem de realização das entrevistas.

A Tabela 1 contém uma breve caracterização da amostra, considerando gênero, idade e escolaridade (por se tratar de respondentes de uma empresa específica, outros dados complementares não foram disponibilizados, com a finalidade de preservar seu anonimato).

Tabela 1

Caracterização da amostra da pesquisa

\begin{tabular}{cccc}
\hline Participantes & Gênero & Idade & Escolaridade \\
\hline P1 & F & 57 & Pós-graduação \\
P2 & M & 66 & Ensino Médio \\
P3 & M & 57 & Pós-graduação \\
P4 & M & 60 & Ensino Superior \\
P5 & F & 63 & Pós-graduação \\
P6 & M & 61 & Ensino Médio \\
P7 & M & 60 & Ensino Superior \\
P8 & F & 63 & Pós-graduação \\
P9 & F & 55 & Pós-graduação \\
P10 & M & 62 & Pós-graduação \\
P11 & M & 62 & Pós-graduação \\
P12 & M & 56 & Pós-graduação \\
P13 & M & 66 & Ensino Superior \\
\hline
\end{tabular}

\section{Instrumentos e Procedimentos}

Para o levantamento dos dados foram utilizados dois instrumentos: a técnica da trajetória sócio profissional (Gaulejac, 2014), em versão adaptada e a entrevista semiestruturada. Como um dos objetivos do estudo diz respeito a compreender o papel do trabalho na vida das pessoas durante a carreira, em comparação aos outros papéis (estudo, família, tempo livre e comunidade), a técnica da trajetória sócio profissional foi adaptada e utilizada para tal finalidade. Neste sentido, foram feitas duas modificações em relação à versão original: o preenchimento do Genograma foi realizado até a primeira geração familiar ascendente e descendente (o original analisa até a segunda geração); na construção da linha da vida foram mantidas a trajetória escolar (estudo), profissional (trabalho) e relações familiares (família e casa), que possuem relação direta com os papéis que estavam sendo investigados, enquanto os aspectos sociais, políticos e econômicos, foram retirados e substituídos pelos itens tempo livre e comunidade.

Antes da coleta qualitativa foi realizado estudo piloto com dois aposentados da empresa para verificar a adequação da técnica da trajetória sócio profissional adaptada e o ajuste semântico das questões do roteiro de entrevista. $\mathrm{O}$ estudo piloto é um instrumento valioso que proporciona ao pesquisador mais experiência sobre o seu contexto de pesquisa antes da coleta principal, podendo revelar falhas sutis a serem revisadas antes da execução do estudo (Bailer, Tomitch, \& D’Ely, 2011). Não houve necessidade de modificação da técnica da trajetória sócio profissional após a aplicação do estudo piloto; já em relação ao roteiro de entrevista, uma questão foi retirada e outras duas foram inseridas.

$\mathrm{Na}$ coleta dos dados, que aconteceu entre os meses de abril e junho de 2016, todos os participantes assinaram o Termo de Consentimento Livre e Esclarecido, preencheram o formulário da técnica da trajetória sócio profissional e, em seguida, participaram das entrevistas que foram gravadas em áudio, com o prévio consentimento do participante, e depois foram transcritas. A duração das entrevistas variou de 37 a 84 minutos. Os conteúdos das entrevistas e da técnica da trajetória sócio profissional foram compreendidos e classificados de forma conjunta, por meio da análise de conteúdo (Bardin, 2011), especialmente pela utilização da técnica de categorização temática.

\section{Resultados e Discussão}

Conforme pode ser percebido na tabela 2 os resultados da pesquisa foram analisados a partir de três eixos temáticos: 1) Trabalho e Carreira; 2) Aposentadoria e 3) Satisfação de Vida. 
Tabela 2

Eixos temáticos e subcategorias de análise

\begin{tabular}{ccc}
\hline Eixos Temáticos & \multicolumn{1}{c}{ Subcategorias } & \multicolumn{1}{c}{ Síntese das Subcategorias } \\
\hline 1. Trabalho e Carreira & Significado do trabalho & Significado do trabalho e da carreira. \\
& Papéis & $\begin{array}{l}\text { Divisão do tempo e investimento de interesse } \\
\text { entre os papéis. }\end{array}$
\end{tabular}

2. Aposentadoria Significado da aposentadoria

Fonte: Dados da Pesquisa (2016)

Processo de preparação

Tipo de decisão tomada

Mudanças/similaridades percebidas
Perspectiva Positiva, Perspectiva Negativa, Perdas por não pertencer mais à empresa, Medos da depressão, da velhice e da falta de dinheiro.

A influência do PPA no ajuste e a preparação financeira.

A continuidade do Trabalho na mesma área, em área diferente, a aposentadoria definitiva, o Trabalho voluntário.

Ritmo de vida, organização do tempo, necessidade de substituição do papel social do trabalho (Status, reconhecimento, amizades), necessidade de se sentir útil.

\section{Satisfação de Vida Categoria única}

Fatores que influenciam a satisfação de vida e ajuste na aposentadoria: fator financeiro, a rede social e familiar de apoio, a voluntariedade/ involuntariedade da decisão de aposentar e a realização de trabalho voluntário.

\section{Trabalho e Carreira}

Nesta categoria, denominada "Trabalho e Carreira", são tratados os aspectos relacionados ao significado do trabalho e da carreira, especialmente, no que diz respeito à divisão do tempo e do investimento de interesse, entre os papéis desempenhados no decorrer da vida. Segundo Bendassolli, Alves e Torres (2014, p.177), “ao trabalhar, as pessoas produzem interpretações acerca de seu fazer, dos propósitos de sua ação, dos objetivos que pretendem alcançar". Mais do que isso, elas fazem um planejamento de vida, baseado em expectativas que pretendem realizar por meio do fazer laboral. Em relação a essa questão, para os entrevistados, parte do significado do trabalho durante a carreira esteve atrelado à concepção do trabalho, como condição para a realização dos projetos de vida, conforme pode ser percebido pelo relato de P3: "Na minha vida toda, trabalho foi a realização de sonhos. Nunca trabalhei por salário, sempre foi uma consequência. É um objetivo pessoal, você tem que ter sucesso, ter resultado sabe?" (P3, masculino).
O trabalho também foi percebido como propiciador de dignidade, do sentimento de utilidade e de independência financeira, servindo, dessa forma, como catalizador para o atingimento dos objetivos de vida, o que vai ao encontro da reflexão de Trigueiro (2010, p.23), ao afirmar que "na atualidade, o trabalho satisfaz três necessidades fundamentais da natureza humana: a necessidade de subsistir (função econômica), a de criar (função psicológica) e a de colaborar (função social)". Pode-se perceber tal conexão a partir do relato de P11.

“Trabalho além de ser um meio de sustento necessário para a sobrevivência, é também, acima de tudo, uma forma de a gente vir para esse mundo, tornar-se útil para a sociedade, desempenhar nosso papel de bom cidadão, bom cristão, honesto cidadão e é através do trabalho que a gente vai se dignificar e fazer algo pela sua existência nesse mundo. Sem trabalho ninguém consegue ser alguém na vida." (P11, masculino)

Em relação à maneira como os participantes procuravam dividir o tempo e a dedicação a cada um dos papéis 
da vida, foram visualizadas dificuldades em manter o equilíbrio entre a vida pessoal e a profissional, em função das demandas relacionadas ao trabalho, o que pode ser percebido pela fala de P5: "Eu trabalhava muito, em torno de dez horas por dia, costumava também ir aos finais de semana para arrumar a papelada que não tinha dado tempo durante a semana. Com isso não sobrava muito tempo para fazer outras coisas." (P5, feminino).

Ainda em relação à dedicação excessiva ao trabalho, percebe-se que tal comportamento, gerou impactos na dinâmica familiar como, por exemplo, percepções e sentimentos de ausência, seja por parte dos próprios entrevistados e/ou de seus familiares, especialmente em relação à participação no desenvolvimento dos filhos, o que pode ser conferido norelato de P3: "Eu sempre trabalhei demais, por exemplo, os meus filhos, um eu não vi começar a andar e o outro eu não vi começar a falar. Eu viajava demais, eu era muito ausente." (P3, masculino).

Em relação ao papel de casa e família, no que tange a ocupação com a divisão das tarefas relacionadas à organização da rotina, aparecem diferenças de acordo com o gênero dos participantes. Enquanto para os homens, esteve presente a ideia de "ajuda" nas tarefas domésticas, para as mulheres ser responsável por tais atividades aparece de forma naturalizada, corroborando resultados de estudos anteriores (Silva, 2015), que apontam a distribuição não igualitária das tarefas da casa entre os casais em que ambos trabalham fora, acarretando sobrecarga e estresse nas mulheres: "minha esposa que atendia mais a parte da casa, ela trabalhava também, mas tinha mais tempo e ficava responsável pela casa." (P13, masculino).

A prática das mulheres, de articularem todas as atividades possui um preço alto, pois resulta em intensa exigência e cansaço, o que implica em um conflito de gerenciamento do tempo, em função "da sobreposição de tarefas entre casa e trabalho, divisão de tarefas desiguais entre elas e os cônjuges e exigências de dedicação de tempo do trabalho remunerado" (Silva, 2015, p.97). Em relação ao cuidado com os filhos e a organização do tempo para estar com eles, os relatos mais expressivos apareceram, especialmente, na fala de três mulheres e de um homem - o qual era divorciado e mantinha a guarda dos filhos. Tais relatos parecem corroborar, mais uma vez, a demonstração de desequilíbrio na divisão das tarefas domésticas. A fala de P9 clarifica tal afirmação.

"E sempre me organizando, levando, buscando, mas eu nunca deixei de trabalhar. Então eu sempre conciliei, eu reconheço que foi um papel pesado, a gente tinha que dar conta, eu acho que a mulher tem uma carga pesada, mas mesmo assim acho que as mulheres não devem abrir mão de ter uma família, especialmente de ter filhos." (P9, feminino)

Se em relação ao papel de casa e família foram percebidas discrepâncias de gênero, o mesmo não ocorreu em relação ao papel do estudo. A dedicação ao mesmo permeia várias etapas da vida dos participantes e ambos os sexos mencionaram o empenho necessário para conseguirem conciliar, atividades de estudo e de trabalho em diversos momentos da carreira. Tal resultado pode estar relacionado ao fato de que o papel de estudo está intrinsecamente relacionado ao papel de trabalho, tendo em vista que o aprofundamento dos conhecimentos serve como preparação para a continuidade no desenvolvimento da carreira, sendo que as exigências de qualificação modificam-se de acordo com o patamar que se quer alcançar, conforme relato de $\mathrm{P} 4$ :

"Eu sempre estudei à noite (...) eu fiz curso técnico de noite, faculdade de noite e aí quando eu vim pra Gama, começou a necessidade do inglês (...) então teve época que eu chegava a fazer 5 horas por noite de inglês, depois do trabalho (...) e fora isso eu fiz 'trocentos' milhões de cursos de gerenciamento que geralmente eram final de semana né?" (P4, masculino)

Se, por um lado, a dedicação aos estudos esteve presente no decorrer da carreira, o mesmo não aconteceu em relação aos relatos de participação ativa no papel da comunidade. Diversos motivos foram mencionados para tal afastamento como, por exemplo, a falta de tempo, o caráter enfadonho de alguns tipos de atividade e o desinteresse para o envolvimento com questões políticas. Quando questionados a respeito do papel do lazer durante a vida, os participantes relataram viagens de final de semana, almoços em família, hobbyes pessoais, bem como a realização de esporte com amigos. Nessa subcategoria, também apareceu, recorrentemente, a tentativa de organizar o tempo para conseguir conciliar a demanda de trabalho com as atividades de lazer, como pode ser percebido no relato de P1:

"O que fica para as minhas filhas, que elas sempre comentam é que a gente sempre fazia coisas, sempre saíamos para a praia, passeávamos. Eu sempre tentei pegar horários aqui de final de semana que fosse de madrugada para que quando fosse às oito da manhã, eu saía e quando chegava em casa elas ainda estavam acordando aí era como se nada tivesse acontecido, (risos)." (P1, feminino) 
Nesta primeira categoria de análise dos dados foram abordados aspectos relacionados ao significado do trabalho e a distribuição do tempo entre os papéis desempenhados no decorrer da carreira. Os relatos demonstram, de maneira em geral, comportamentos de prevalência do investimento de tempo e interesse no papel do trabalho, em detrimento da dedicação com outras esferas da vida. Com a aproximação da aposentadoria, o que, em tese, estaria relacionado à diminuição ou ao desligamento das atividades de trabalho, surge a necessidade de compreender quais estratégias esses trabalhadores utilizaram na redistribuição do tempo dedicado a cada um dos papéis (trabalho, estudo, família, lazer, comunidade), tendo em vista que passaram a vida dedicando maior tempo ao papel do trabalho por terem exercido suas atividades profissionais em uma multinacional cujas exigências de desempenho e comprometimento com o trabalho se faziam presentes.

\section{A Aposentadoria}

O período da aposentadoria caracteriza-se como uma transição que pode ser concebida como um momento de crise ou de liberdade (Zanelli, Silva, \& Soares, 2010). Para Leandro-França (2014), aspectos pessoais, psicossociais e organizacionais, costumam influenciar tal fenômeno. Dessa forma, nesta segunda categoria, buscou-se investigar quais fatores influenciaram as distintas percepções entre os participantes da pesquisa. Para tal, os resultados foram divididos em quatro subcategorias, quais sejam: significado da aposentadoria, processo de preparação, tipo de decisão tomada e mudanças e/ou similaridades percebidas.

Para alguns entrevistados, tornar-se aposentado estava atrelado à percepção do início de uma nova etapa de vida, que permite o desfrute de um período de escolha para fazer o que se gosta, para a realização de sonhos e planos, o que pode ser conferido a partir do relato de P9: "Aposentadoria significa uma nova etapa onde você vai usufruir de tudo aquilo que construiu. (...) É uma chance de você repensar a sua vida e fazer as coisas que não teve a oportunidade de fazer, justamente por falta de tempo." ( $\mathrm{P} 9$, feminino).

Se, por um lado, o significado da aposentadoria foi concebido por alguns participantes como um período de desfrute do que se construiu no decorrer da vida, por outro lado, alguns entrevistados mencionaram angústias relacionadas às perdas ocasionadas pelo desligamento da empresa/trabalho. Dentre elas, evidenciou-se, por exemplo, a ausência de status por não pertencer mais à empresa, retratada na fala de P2: "Antes quando eu chegava nos lugares era super bajulado, mas você saiu de lá, esquece, teu sobrenome não vale mais." (P2, masculino). A ausência do reconhecimento pessoal, por não ser mais parte da organização que anteriormente chancelava a identidade dos participantes perante o mercado, vai ao encontro do que afirmam Zanelli et al. (2010), ao considerarem que na perspectiva psicológica, o trabalho é uma categoria central no desenvolvimento do autoconceito e uma fonte importante de autoestima. Para Krawulski et al., 2017 (p.61), "enquanto a continuidade na carreira for marcada pelos sentimentos de reconhecimento e de realização, a perspectiva da aposentadoria é percebida como vazio, perda e ruptura".

Em que pese, para alguns participantes ter sobressaído, com o advento da aposentadoria, a perda do status social e do reconhecimento, para outros, a ênfase maior esteve relacionada à ruptura do convívio social que o ambiente laboral propiciava, no sentimento de não ser lembrado, fazendo-os perceber que o "pertencer" estava atrelado ao "ser empregado" da empresa Gama e a estar fisicamente no ambiente organizacional, como se pode observar no relato de $\mathrm{P} 6$ :

\begin{abstract}
"Eu imaginava que esse convívio social fosse mantido por um periodo maior, mas não é bem assim! Quem não é visto não é lembrado. Quando você tá ali na sua mesa, todo mundo te chama para as coisas, mas agora ah, vamos chamar o cara. Vamos chamar o cara? É uma vez, duas e depois o cara passa a não existir mais, então realmente você tem que começar a fazer parte de um novo ciclo de amizades." (P6, masculino)
\end{abstract}

As relações de amizade mantidas durante a carreira, muitas vezes não são continuadas após o desligamento. Apesar de mencionar que tal aspecto do isolamento social costuma ser enfatizado no programa de preparação para a aposentadoria oferecido pela empresa, P6 afirma que: " $\mathrm{eu}$ não achei que fosse fazer falta, entende, por que eu tinha um relacionamento muito bom com o pessoal, pensei ah, isso vai continuar, a gente vai estar bem, sabe, mas na verdade faz falta, te tiram da teia!" (P6, masculino). Ainda para este pesquisado, depois de um período de choque e de depressão, devido ao isolamento social, se percebe a necessidade de criar novos círculos sociais que propiciem o sentimento de fazer parte de um grupo novamente. Para Roesler (2014), a transição para a aposentadoria é caracterizada como um período cercado de contradições e de ambivalências, "ora a euforia de poder usufruir a sonhada liberdade, ora o medo da perda dos vínculos sociais oportunizados no e pelo trabalho e de não saber o que fazer de si e do tempo que se descortina em seu horizonte" (p. 77). 
A ênfase conferida ao papel do trabalho durante a carreira e o estreitamento das relações com os colegas faz com que o desligamento da empresa seja caracterizado também pelo enfraquecimento dos vínculos sociais quando estes não estão estruturados para além do cenário laboral.

Outra perda relatada de maneira recorrente pelos entrevistados estava relacionada ao fantasma da associação da aposentadoria com depressão e morte, especialmente, quando os participantes se remetiam a aposentadoria de parentes próximos. A respeito disto, P1 relata que: "Eu tinha um pai que gostava de ler, de pesquisar coisas, mas quando ele se aposentou, ficou sentadinho no sofá esperando a morte chegar e eu falei 'geeennte', eu não quero isso para mim, tenho que pensar em alguma coisa!" (P1, feminino).

O receio de passar dificuldades financeiras na aposentadoria e a associação da ausência de dinheiro com depressão e morte, também foram descritas pelos entrevistados, como pode ser conferido no depoimento de P2: "Então eu deduzi claramente por que o cidadão fica doente: falta de dinheiro. Por que se você guardou, bem, se não guardou fica no buraco." (P2, masculino). Percebe-se, a partir dos relatos, a existência de um imaginário, por parte dos entrevistados, de que a estabilidade financeira é uma condição para afastar qualquer tipo de mazela relacionada à depressão e a morte, como pode ser observado no relato de P12 “(...) com um salário mínimo você acaba caindo num processo vicioso que acaba caindo em depressão e morre. Então se tiver um processo financeiro que te permita manter um padrão legal após aposentadoria, o resto é consequência" (P12, masculino).

Apesar de em pesquisas anteriores (Amorim et al., 2017; Bonsang \& Klein, 2012) a condição financeira ser apontada como um dos fatores principais para o sentimento de satisfação de vida e ajuste na aposentadoria, algumas vezes, a queda do padrão de vida, relatada geralmente como principal problema, encobre o vazio existencial causado pela ausência das atividades laborais (Roesler, 2014). Em se tratando dos participantes da presente pesquisa, vale ressaltar que além de terem direito ao benefício do INSS, os aposentados pela Gama também contam, em sua grande maioria, com os proventos oriundos da previdência privada da empresa (Gamaprev) o que proporciona a eles uma condição financeira relativamente estável.

Em relação a esta questão, Roesler (2014), em pesquisa com quinze executivos bancários aposentados de alto nível econômico, afirma que alguns entrevistados se referem à situação financeira como fonte de preocupações e de sofrimento, mesmo tendo acumulado o suficiente para viver confortavelmente até o fim de suas vidas. Tal afirmação vai ao encontro do que relata P2: "Eu me preparei monetariamente, mas não psicologicamente. A minha mulher disse que quando eu me aposentei, eu tava em casa, parecia um cachorro que caiu da mudança, insuportável!" (P2, masculino). Percebe-se que passar a organizar as atividades do dia a dia, sem a estruturação da rotina propiciada pelos horários de entrada e saída do emprego, configura-se como desafio para grande parte dos entrevistados.

Uma alternativa utilizada pelas empresas com a finalidade de minimizar as perdas relacionadas ao papel do trabalho e facilitar o ajuste na fase da aposentadoria são os programas de preparação para esse período da vida. Para Seidl, Leandro-França e Murta (2014), o planejamento precoce, realizado no decorrer da carreira, pode otimizar os ganhos e fortalecer os fatores de proteção que propiciam o bem-estar e a felicidade na aposentadoria. As mesmas autoras afirmam ainda que tal preparação precisa ser compreendida como um processo de educação para a aposentadoria, com abrangência de ações que fomentem o refletir sobre projetos de vida muitos anos antes da aposentadoria, contemplando não somente os adultos-idosos, mas adultos jovens em diversos momentos da carreira, permitindo dessa forma que "eles (re)construam seus projetos de vida a curto, médio e longo prazo" (Seidl, et al. 2014, p.86).

O programa de preparação para a aposentadoria da empresa Gama propicia a participação de pessoas em diferentes estágios da carreira e costuma ser bem avaliado pelos que dele participam. Apesar de reconhecerem que o programa oferecido pela empresa é de alta qualidade e que contribui bastante para o planejamento para uma nova fase, alguns participantes relataram as dificuldades que tiveram com a organização da vida, especialmente após a formalização do desligamento, como pode ser percebido pela fala de P6: "Eu fiz o programa de preparação por dois ou três anos, mas o pior é quando chega na realidade. Faço várias atividades, e mesmo assim eu senti uma depressão que a falta do trabalho ocasiona sabe." (P6, masculino). O mesmo participante comenta ainda sobre a necessidade das empresas darem "uma sustentação maior nessa fase final, para que o trabalhador que tá parando tenha realmente um suporte ai e um direcionamento do que deve ser feito, isso faz falta." (P6, masculino). O relato de P6 corrobora estudos anteriores (Earl, Bednall, \& Muratore, 2015; França et al., 2014), os quais apontam, para a necessidade de planejamento e de avaliação após a aposentadoria.

Em pesquisa realizada com 207 gestores de empresas brasileiras responsáveis por programas de preparação para a aposentadoria, França et al. (2014), revelaram que são raras as organizações que continuam acompanhando os 
aposentados após eles terem se desligado da instituição. A esse respeito, Earl et al. (2015), apontam para o perigo de concentrar no planejamento apenas no período anterior à aposentadoria e ressaltam para a relevância deste centrar-se na vida atual dos aposentados e não somente no período prévio à aposentadoria.

Apesar dos Programas de Preparação serem concebidos, de maneira em geral, com a finalidade de auxiliar na reflexão sobre a substituição do papel de trabalho por outros interesses no período da aposentadoria (Boehs et al., 2017), tentando evitar um possível vazio existencial, oriundo da ausência do trabalho, estudos anteriores (Wang et al., 2011), apontam que, geralmente, o fator de maior preocupação dos aposentados, está relacionado à condição financeira. Na presente pesquisa não foi diferente, pelo relato dos participantes percebe-se que houve uma preparação formal (consultor financeiro oferecido pela Gama) e informal (realização de investimentos financeiros ao longo da vida), especialmente com o objetivo de não ter que passar por dificuldades similares as que vivenciaram seus familiares, como pode ser percebido pelo relato de P2: "Como eu tinha exemplos em casa de dificuldades de tios e dos meus dois irmãos... então eu investia dinheiro. Guardava, investia, nunca fui de jogar dinheiro fora (...)" (P2, masculino). Yeung \& Zhou (2017) ao aplicarem três avaliações subsequentes com 118 aposentados chineses descobriram que os aposentados com mais atividades preparatórias antes da aposentadoria apresentavam melhores recursos financeiros que contribuíam para mudanças positivas na aposentadoria e para o bem-estar ao longo do tempo. Assim, os relatos das entrevistas corroboram os resultados do trabalho de Earl et al. (2015), quando mencionam que ter vivido eventos de conotação negativa no passado podem influenciar no comportamento do planejamento contra perdas futuras. Especialmente, aqueles participantes, que no Genograma mencionaram advir de famílias com vulnerabilidade socioeconômica e terem passado dificuldades financeiras na infância tendo começado mais cedo o planejamento financeiro para a aposentadoria.

Como as entrevistas foram realizadas com aposentados que se encontravam em diferentes condições de trabalho (realizando atividades remuneradas, sem trabalhar e realizando trabalho voluntário), procurou-se verificar se tal status de trabalho influenciava de alguma forma no ajuste e na satisfação de vida na aposentadoria. Entre aqueles ainda empregados na Gama, o principal motivo relatado para a permanência no trabalho estava ligado ao fator financeiro, especialmente por possuírem filhos dependentes, estudando em faculdades particulares, o que vai ao encontro do estudo anterior (Wang et al., 2011) de que possuir filhos dependentes, influencia negativamente no processo de ajuste na aposentadoria

Entre os participantes que estavam trabalhando ou pretendiam trabalhar durante a aposentadoria em área diferente da carreira regular, a continuidade do exercício profissional apareceu como uma possibilidade de flexibilização da jornada de trabalho e da descoberta de novas habilidades, conforme pode ser percebido pelo relato de P9: "E o que me surpreendeu foi isso, descobrir depois que você para de trabalhar que você tem capacidade e condições de fazer outras coisas que durante o tempo que está preso naquela rotina das oito às cinco, você não enxerga!" (P9, feminino).

Entre aqueles que optaram por não realizar atividade remunerada na aposentadoria, a questão mais apontada pelos entrevistados esteve cercada por um paradoxo, pois ao mesmo tempo em que relataram a infelicidade por não estarem utilizando suas capacidades criativas, também comentaram sobre a ausência de contrapartida financeira justa oferecida pelas empresas que valorizasse a experiência profissional que eles adquiriram ao longo da carreira, como pode ser conferido pelo relato de P2: "Todo o conhecimento que eu tenho eu não consigo passar, só de graça (...) tem muitas empresas aí que você vai cobrar mil reais num treinamento e eles dizem que não podem gastar." ( $\mathrm{P} 2$, masculino). Em contrapartida, entre aqueles que não executam atividade remunerada, mas estão envolvidos com trabalho voluntário parece haver um melhor ajuste à condição de aposentados, conforme pode ser percebido pelo relato de P11, que faz 20 horas semanais de trabalho voluntário: "Não tenho nenhum dia que eu poderia te dizer assim que eu fiquei amargurado, chateado, com vontade de trabalhar." (P11, masculino). Segundo Leandro-França e Murta (2014), "o voluntariado pode proporcionar estabilidade e suporte na transição para a aposentadoria" (p.39) gerando sentimentos de bem-estar e prazer.

Algumas mudanças e/ou similaridades foram percebidas quando os participantes compararam o tipo de vida que levavam durante a carreira, com a que possuem na aposentadoria. As principais mudanças relatadas foram em relação ao ritmo de vida, à organização do tempo e ao preenchimento das lacunas sociais deixadas pela ausência do ambiente de convivência do trabalho. Já a maior similaridade, não raro, esteve relacionada com a manutenção da necessidade de sentir-se útil o que ratifica estudos anteriores (Krawulski et al., 2017; Zanelli et al., 2010) que apontam para o mesmo caminho. Para Krawulski et al. (2017, p. 62), "a chegada da aposentadoria e a possibilidade de possuir uma agenda mais flexível e aberta criam um paradoxo para os profissionais: ela é desejada, como 
descanso merecido após anos de dedicação, porém também temida, por trazer consigo incertezas e readequações iminentes".

Em relação à distribuição do tempo, algumas pessoas relataram a satisfação por possuírem maior flexibilidade de horário, como pode ser percebido pela fala de P8: "É a liberdade de fazer o que você quer, na hora que quer né? Então até hoje, eu já estou aposentada a um bom tempo, às vezes termino alguma atividade de consultoria em alguma empresa ai vou pro shopping." (P8, feminino). Outra mudança relatada foi em relação à percepção da escassez das atividades sociais outrora frequentes pelo contato com os colegas de trabalho e o esforço para a substituição desses eventos por atividades que compensem as lacunas deixadas, como pode ser averiguado pelo relato de P6: "Por que antes toda sexta feira a gente tomava uma cerveja, a cada dois dias tinha um coquetel. Hoje não tem, hoje o que você faz? Você vai ao cinema, então você cumpriu aquela lacuna social sabe?" (P6, masculino).

A principal similaridade observada entre a vida da carreira e durante a aposentadoria foi a busca pela realização de inúmeras atividades, visando manter-se útil e produtivo, como pode ser percebido pelo relato de P12, "Não dá pra parar né? Por que parar, sentar na frente da televisão e por o pijama, é morte né? Então tem que rodar né?" (P12, masculino). Tal busca por sentir-se útil vem ao encontro de autores da teoria da continuidade (Atchley, 1989; Fontoura, Doll, \& Oliveira, 2015) que consideram que o ser humano tende a possuir padrões de comportamento duradouros durante o ciclo de vida. Dessa forma, a busca desenfreada por atividades que ocupem o tempo de maneira útil seria uma maneira de dar continuidade a uma rotina construída e permeada pelo trabalho ao longo da vida, o que, por decorrência, se vincula à satisfação de vida.

\section{Satisfação de vida}

Por fim, na última categoria, foram encontrados quatro fatores que influenciam sobremaneira, a satisfação de vida e o ajuste na aposentadoria, sendo eles: a dimensão financeira, a rede social e familiar de apoio, a voluntariedade/involuntariedade da decisão de aposentar, e a realização de trabalho voluntário. $\mathrm{O}$ fator financeiro foi o que apareceu de forma mais recorrente em relatos, tanto associando a suficiência de dinheiro com a satisfação de vida, quanto com a ausência do mesmo, sendo gerador de insatisfação, o que ratifica estudos anteriores (Amorim et al., 2017; Bonsang \& Klein, 2012). Tais elementos podem ser percebidosno relato de $\mathrm{P} 3$ :
"Ah... (silêncio), eu tô em desmerecimento. Eu não tô satisfeito, lógico que não né? Muito difícil, acordar de manhã pensando em dinheiro, nunca foi assim. Eu acordava de manhã pensando no que eu ia fazer né, se ia trocar de carro. Nunca fui materialista, sempre fui mais espiritualista, mas hoje eu estou insatisfeito." (P3, masculino)

Fazer parte de uma rede social familiar e/ou de amizades consideradas significativas foi apontado pelos participantes como fundamental para o sentimento de satisfação com a vida, conforme podemos perceber no relato de P13: "Ter atividade, ter a familia, amigos (...), eu tenho diversos grupos de amigos. Tem o grupo da faculdade, tem a turma do colégio (...) então com isso a gente mantém os amigos, e isso é uma das partes mais importantes." (P13, masculino). Tais resultados corroboram estudos anteriores (Heybroek, 2011; Heybroek et al., 2015) que apontam o apoio social, o contato com a família e com amigos como antecedentes do alto nível de satisfação com a vida após a aposentadoria.

A voluntariedade / involuntariedade da decisão de aposentadoria também se relaciona com a satisfação de vida, conforme pode ser observado pelos relatos de P8 e P5, respectivamente. Por exemplo, P8 (feminino), que se aposentou voluntariamente, se considera muito satisfeita com o tipo de vida que leva atualmente, "Eu me aposentei por vontade própria e estava assim com a cabeça muito feita. As pessoas falavam: Você não pegou o carro e foi para a Gama nenhum dia? Claro que não!" e ressalta ainda que "a liberdade de ir e vir de fazer o que você quer na hora que você quer" como o principal fator que influencia a sua satisfação. Por outro lado, P5 (feminino) que não se aposentou por vontade própria, relata que a involuntariedade da decisão gerou a insatisfação por não ter podido se reorganizar financeiramente da forma como desejava "eu queria ter mais grana, maiores condições financeiras, por que depois que você deixa de trabalhar, o teu patamar passa a ser outro". Pesquisas anteriores (Bonsang \& Klein, 2012; Dingemans \& Henkens, 2014; Wang et al., 2011), também apontam na direção de que a voluntariedade da decisão de aposentadoria está positivamente relacionada ao processo de ajuste e a satisfação de vida. A voluntariedade da decisão se refere à possibilidade da escolha no processo do aposentar-se, $\mathrm{o}$ que psicologicamente propicia ao trabalhador a percepção de controle sobre a decisão gerando sentimentos de satisfação com a vida.

Dedicar-se à espiritualidade e realizar trabalho voluntário foram outros dois fatores que apareceram como fonte de satisfação de vida e ajuste na aposentadoria, 
conforme podemos perceber no relato de P11. "Hoje o trabalho voluntário e a fé são pontos fortes na minha vida (...) a parte espiritual sempre teve um papel importante, mas como aposentado ela é importantíssima, (...) nesses dois anos como aposentado eu estou completamente realizado." (P11, masculino). Tal dado vem ratificar resultados de pesquisas anteriores que indicam que realizar trabalho voluntário (Wang et al., 2011) e estar ligado a questões espirituais (Sommerhalder \& Goldstein, 2016) associa-se com uma melhor qualidade e satisfação de vida na aposentadoria e no envelhecimento.

\section{Considerações finais}

O presente estudo contribuiu para a compreensão dos fatores que influenciam a satisfação/insatisfação de vida e ajuste na aposentadoria, em um grupo específico de aposentados que tiveram como último empregador uma organização privada, contratante pelo regime da Consolidação das Leis do Trabalho (CLT). A amostra possui características específicas, tais como, alto nível de escolaridade e renda tendo em vista que os participantes construíram suas carreiras em uma empresa multinacional de grande porte, com baixos índices de rotatividade e que estimula o desenvolvimento da carreira na própria organização. $\mathrm{O}$ presente estudo se diferencia de pesquisas anteriores tendo em vista que foi realizado com trabalhadores da iniciativa privada que já se encontravam efetivamente aposentados. No Brasil a maior parte das pesquisas sobre aposentadoria vem sendo realizadas com trabalhadores de empresas públicas (França et al., 2014) e com trabalhadores no período anterior à aposentadoria (Boehs et al., 2017). Apesar de a pesquisa ter sido realizada com profissionais aposentados de uma multinacional, o estudo é importante por ser representativo desse contexto específico. A realização de pesquisas que contemplem aposentados oriundos de diferentes configurações (empresas privadas e públicas de portes distintos, profissionais liberais e autônomos) pode vir a enriquecer as descobertas sobre os fatores que influenciam a satisfação de vida na aposentadoria.

Os resultados apontam na direção de ser importante desmistificar o conceito de que a aposentadoria se caracteriza por uma etapa de não atividade e descanso. Para alguns, o que traz satisfação de vida nessa fase pode ser o desligamento total das atividades de trabalho, enquanto para outros não. Além do que, a aposentadoria não se configura pela desvinculação de qualquer tipo de trabalho, sendo que a realização de ações não remuneradas como, por exemplo, atividades de voluntariado, comunitárias, sociais, familiares, de lazer ou de estudo, permitem uma nova configuração de organização do tempo antes ocupado pelas atividades laborais.

A partir dos conteúdos apresentados e considerando os objetivos deste estudo, destaca-se a importância dos gestores e demais trabalhadores atentarem para a importância da distribuição equilibrada entre os diversos papéis desempenhados no decorrer da vida, como forma de propiciar a manutenção dos vínculos sociais, familiares e de amizade, em outras esferas, além do ambiente laboral. Por fim, reforça-se também, a necessidade de que haja o acompanhamento psicossocial dos aposentados por um período após a efetivação do desligamento do trabalho, pois apesar dos programas de preparação auxiliarem no planejamento para a aposentadoria, as maiores dificuldades de organização do tempo físico e social são enfrentadas justamente quando o trabalhador está efetivamente aposentado.

\section{Referências}

Amorim, S. M., França, L. H. F. P., \& Valentini, F. (2017). Predictors of happiness Among retired from urban and rural areas in Brazil. Psicologia: Reflexão e Crítica, 30(2). DOI: https://dx.doi.org/10.1186/s41155-016-0055-3

Atchley, R. C. (1989). A continuity theory of normal aging. The Gerontologist, 29, 183-190. DOI: http://dx.doi. org/10.1093/geront/29.2.183

Bailer, C., Tomitch, L. M. B., \& D’Ely, R. C. S. (2011). Planejamento como processo dinâmico: a importância do estudo piloto para uma pesquisa experimental em linguística aplicada. Revista Intercâmbio, 24, 129-146. Recuperado em 18 junho 2017, de https://revistas.pucsp.br/index.php/intercambio/article/view/10118

Bardin, L. (2011). Análise de conteúdo. São Paulo: Edições 70.

Bendassolli, P. F., Alves, J. S. C., \& Torres, C. C. (2014). Inventário sobre significado do trabalho de profissionais de indústrias criativas. Avaliação Psicológica, 13(2), 177-186. Recuperado em 18 junho 2017, de http://pepsic.bvsalud. org/pdf/avp/v13n2/v13n2a05.pdf

Boehs, S. T. M., Medina, P. F., Bardagi, M. P, Luna, I. N., \& Silva, N. (2017). Revisão da Literatura latino-americana sobre Aposentadoria e Trabalho: Perspectivas Psicológicas. Revista Psicologia, Organizações e Trabalho, 17(1), 1-9. DOI: https://dx.doi.org/10.17652/rpot/2017.1.11598 
Bonsang, E., \& Klein, T. J. (2012). Retirement and subjective well-being. Journal of Economic Behavior \& Organization, 83(3), 311-329. DOI: 10.1016/j.jebo.2012.06.002

Borges. L. O., \& Yamamoto, O. H. (2014). Mundo do trabalho: construção histórica e desafios contemporâneos. In: J. C. Zanelli, E. Borges-Andrade, \& A. V. Bastos (Orgs.). Psicologia, Organizações e Trabalho no Brasil. $2^{\mathrm{a}}$ edição (25-72). Porto Alegre: Artmed.

Davey, A., \& Szinovacz, M. E. (2004). Dimensions of Marital Quality and Retirement. Journal of Family Issues. 25(4), 431-464. DOI: 10.1177/0192513X03257698

Dingemans, E., \& Henkens, K. (2014). Involuntary retirement, bridge employment, and satisfaction with life: A longitudinal investigation. Journal of Organizational Behavior, 35(4), 575-591. DOI: 10.1002/job.1914

Earl. J. K., Bednall, T. C., \& Muratore, A. M. (2015). A Matter of Time: Why Some People Plan for Retirement and Others Do Not. Work, Aging and Retirement, 1(2), 181-189. DOI:10.1093/workar/wau005

Emmons, R. A. (1986). Personal Strivings: An approach to personality and subjective well-being. Journal of Personality and Social Psychology, 51, 1058-1068.

Fontoura, D. S., Doll, J., \& Oliveira, S. N. (2015).O Desafio de Aposentar-se no Mundo Contemporâneo. Educação \& Realidade, 40(1), 53-79. DOI: 10.1590/2175-623645774

França, L. H. F. P., Nalin, C. P., Siqueira-Brito, A. R., Amorim, S. M., Canella Filho, T. R., \& Ekman, N. C. (2014). A percepção dos gestores brasileiros sobre os programas de preparação para a aposentadoria. Estudos Interdisciplinares sobre o Envelhecimento, 19(3), 879-898.

Gaulejac, V. (2014). A neurose de classe: trajetória social e conflitos de identidade. São Paulo: Via Lettera.

Heybroek, L. (2011). Life Satisfaction and retirement: A Latent Growth Mixture Modelling Approach. Hilda Survey $10^{\text {th }}$ Anniversary Research Conference, University of Melbourne.

Heybroek, L., Haynes, M., \& Baxter, J. (2015). Life satisfaction and retirement in Australia: a longitudinal approach. Work, Aging and Retirement, 1(2), 166-180. DOI: 10.1093/workar/wav006.

Krawulski, E., Boehs, S. T. M., Cruz, K. O., \& Medina, P. F. (2017). Docência voluntária na aposentadoria: transição entre o trabalho e o não trabalho. Revista Psicologia: Teoria e Prática, 19(1), 55-66. DOI: 10.15348/1980-6906/psicologia.

Lassance, M. C., \& Sarriera, J. C. (2012). Adaptação e validação do Inventário de Saliência (Salience Inventory) para adultos brasileiros. Paidéia, Ribeirão Preto, 22(52), 177-186. DOI: 10.1590/S0103-863X2012000200004.

Leandro-França, C. (2014). Aposentadoria: Crise ou Liberdade? Formatos de programas de educação para a aposentadoria. In: S. G. Murta, C. Leandro-França, \& J. Seidl (Orgs.). Programas de educação para a aposentadoria: como planejar, implementar e avaliar. Novo Hamburgo: Sinopsys.

Leandro-França, C., \& Murta, S. G. (2014). Fatores de risco e de proteção na adaptação a aposentadoria. Psicologia Argumento, 32, 33-43. DOI: 10.7213/psicol.argum.32.076.DS03

Leandro-França, C., van Solinge, H., Henkens, K., \& Murta, S. G. (2016). Effects of three types of retirement preparation program: A qualitative study of civil servants in Brazil. Education Gerontology. 42(6), 338-400. DOI: 10.1080/03601277.2016.1139969

Oliveira, M. C. O., Melo- Silva, L. L., \& Coleta, M. F. D. (2012). Pressupostos teóricos de Super: Datados ou aplicáveis à Psicologia Vocacional contemporânea? Revista Brasileira de Orientação Profissional, 13(2), 223-234. Recuperado em 18 junho 2017, de http://pepsic.bvsalud.org/pdf/rbop/v13n2/09.pdf

Roesler, V. R. (2014). Posso me aposentar "de verdade”. E agora? Contradições e ambiguidades vividas no processo de aposentadoria. Curitiba: Alteridade.

Savickas, M. L. (2002). Career Construction: A developmental Theory of Vocational Behavior. In D. Brown \& L. Brooks (Eds.). Career Choice and Development. 4th Ed. San Francisco: Jossey-Bass.

Schweitzer, L., Gonçalves, J., Tolfo, S. R., \& Silva, N. (2016). Bases epistemológicas sobre sentido(s) e significado(s) do trabalho em estudos nacionais. Revista Psicologia Organizações e Trabalho, 16(1), 103-116.

Seidl, J., Leandro-França, C., \& Murta, S. G. (2014). Formatos de programas de educação para a aposentadoria. In S. G. Murta, C. Leandro-França, \& J. Seidl (Orgs.). Programas de educação para a aposentadoria: como planejar, implementar e avaliar. Novo Hamburgo: Sinopsys.

Shultz, K. S., \& Wang, M. (2011). Psychological Perspectives on the Changing Nature of Retirement. American Psychologist, 66(3), 170-179. DOI: 10.1037/a0022411

Silva, S. R. (2015). Estudo sobre o significado e as emoções de mulheres trabalhadoras Frente a articulação de múltiplas atividades. Dissertação de Mestrado, Universidade Tuiuti do Paraná, Curitiba. 
Sommerhalder, C., \& Goldstein, L. L. (2016). O papel da espiritualidade e da religiosidade na vida adulta e na velhice. In E. V. Freitas, L. Py, F. A. X. Cançado, J. Doll, \& M. L. Gorzoni (Orgs.). Tratado de geriatria e gerontologia. $4^{\mathrm{a}}$ ed. (1307-1315). Rio de Janeiro: Guanabara Koogan.

Super, D. E. (1980). A Life-Span, Life-Space Approach to Career Development. Journal of Vocational Behaviour, 16, 282-298. DOI: 10.1016/0001-8791(80)90056-1

Super, D. E., \& Nevill, D. D. (1986). The Salience Inventory: Theory, application, and research. Palo Alto, CA: Consulting Psychologists Press.

Tolfo, S. R., \& Piccinini, V. (2007). Sentidos e significados do trabalho: explorando conceitos, variáveis e estudos empíricos brasileiros. Psicologia e Sociedade. 19, Edição especial 1, 38-46.

Trigueiro, R. P. C. (2010). Percepção das relações entre trabalho remunerado e trabalho voluntário: Um estudo com voluntários da pastoral da criança. Dissertação de mestrado, Universidade Federal do Rio Grande do Norte, Natal.

Wang, M., Henkens, K., \& van Solinge , H. (2011). Retirement adjustment: A review of theoretical and empirical advancements. American Psychologist, 66, 204-213. DOI: http://dx.doi.org.ez46.periodicos.capes.gov.br/10.1037/ a0022414

Yeung, D. Y., \& Zhou, X. (2017). Planning for Retirement: Longitudinal Effecton Retirement Resources and Postretirement Well-being. Frontiers in Psychology, 8, 1-14. DOI: 10.3389/fpsyg.2017.01300

Zanelli, J. C., Silva N., \& Soares, D. H. P. (2010). Orientação para aposentadoria nas organizações de trabalho: Construção de projetos para o pós-carreira. Porto Alegre: Artmed.

Recebido: 01/02/2017

$1^{a}$ revisão: $13 / 12 / 2017$

Aceite final: $15 / 01 / 2018$

Sobre os autores

Samantha de Toledo Martins Boehs é Psicóloga, Mestre em Administração de Empresas, Doutora em Psicologia pela Universidade Federal de Santa Catarina, na área de concentração Psicologia das Organizações e do Trabalho. Docente do Departamento de Administração Geral e Aplicada da Universidade Federal do Paraná.

Narbal Silva é Psicólogo, Doutor em Engenharia de Produção. Docente do Programa de Pós-graduação em Psicologia da Universidade Federal de Santa Catarina e coordenador do Laboratório de Psicologia Positiva nas Organizações e no Trabalho (LAPPOT). 